\title{
ATUALIZAÇÃO DE ESTUDO SOBRE A IDENTIDADE PROFISSIONAL DO PROFESSORES DE LÍNGUA INGLESA NO CONTEXTO BRASILEIRO ${ }^{1}$
}

\author{
EL KADRI, Michele Salles - UEL
}

RESUMO: O objetivo deste trabalho é atualizar o estudo bibliográfico de pesquisas que abordam a questão da identidade de profissional do professor de língua inglesa no Brasil realizado em 2007 por Quevedo-Camargo e Ramos (no prelo), por meio de levantamento eletrônico. Desse modo, nos concentraremos nas publicações realizadas após o estudo de 2007, abordando, portanto, as pesquisas que datam de 2006 até outubro de 2008 de maneira a verificar tanto as contribuições destes estudos quanto as possíveis descobertas e diferenças do estudo anterior. Visa igualmente a contribuir para um inventário de elementos constitutivos da identidade do professor de língua inglesa no cenário brasileiro. Foram encontrados 6 textos que atendiam aos critérios de busca estabelecidos, sendo 4 artigos e 2 dissertações. De maneira geral, os estudos sobre identidade focam na visão de identidade como construída sócio-historicamente, sempre em processo, multifacetada, não fixa e fragmentada e que tais estudos têm recebido uma crescente atenção por parte dos pesquisadores a julgar pela quantidade de artigos encontrados no âmbito de dois anos - e revisados no escopo deste artigo- se comparado às pesquisas encontradas por Quevedo-Camargo e Ramos (no prelo).

PALAVRAS-CHAVE: levantamento bibliográfico, identidade, professores de língua inglesa.

ABSTRACT: The aim of this paper is to up-date the bibliographic study of studies on the issue of the English language teacher professional identity in Brazil done in 2007 by Quevedo-Camargo e Ramos (in press), by means of electronic search. We focus on the studies published after the 2007, therefore approaching researches from 2006 to October of 2008 aiming at verifying both the contributions of these studies and the possible discoveries and differences in regard to the previous study. We also aim at contributing to form an inventory of constitutive elements of the identity of de English language teacher in Brazil. Six researches meeting the established criteria were found: four articles and two MA dissertations. Overall, the studies about identity define it as being socio-historical-culturally constructed, always in a process, multifaceted, non-fixed and fragmented and that such studies have received growing attention by researchers, considering the amount of articles found within two years and reviewed in the scope of this article - if compared to the researches found by Quevedo-Camargo e Ramos (in press).

KEY-WORDS: bibliographical search, identity, English language teachers.

\section{Introdução}

\footnotetext{
${ }^{1}$ Trabalho apresentado como parte da disciplina "Identidade do Professor de Língua Estrangeira" ministrada no segundo semestre de 2008 pela professora Doutora Simone Reis, do Programa de Pós-Graduação em Estudos da Linguagem da universidade Estadual de Londrina.
} 
Os estudos sobre as identidades sociais têm sido alvo de reflexão tanto nas ciências sociais (BAUMAN, 2005, HALL, 1990) como nos estudos que envolvem linguagem e sujeito (MOITA LOPES, 2002; CORACINI, 2003; BOHN, 2005, BLOCK, 2007). Este interesse se deve principalmente ao fato de vivermos em uma época em que os valores e as concepções de vida até então tidas como "estáveis" e "seguras" estão sendo cada vez mais questionadas e resignificadas. Da mesma maneira, a identidade profissional também sido de interesse de pesquisadores do campo de formação de professores e estudos lingüísticos, justamente por apresentar-se como uma dessas identidades sociais que constituem o sujeito, que co-existem e são co-construídas, da mesma forma que raça, etnia, nacionalidade, migração, gênero e classe social. São também fragmentadas, instáveis, questionadas e estão em "crise" devido a novos paradigmas trazidos pela globalização.

Concordamos com Quevedo-Camargo e Ramos (no prelo) quando afirmam que "a identidade profissional do professor de inglês no Brasil - o que deve saber, o que deve fazer, onde deve atuar -parece, de fato, estar atravessando um momento de crise exatamente porque o panorama educacional no país tem mudado drasticamente nos últimos anos como conseqüência das mudanças em nível mundial”. Acrescentamos que uma dessas "conseqüências" que influenciam diretamente na constituição identitária do professor de língua inglesa é o fato de este ensinar uma língua ligada a processos de homogeneização em tensão com a diversidade. O surgimento de novos paradigmas de ensino de língua inglesa (como por exemplo, os pressupostos trazidos pelo ensino de inglês como língua franca versus o ensino tradicional de inglês como língua estrangeira) exige uma reflexão sobre a identidade profissional do professor de língua inglesa que problematize seu papel diante deste cenário e re-signifique o que este deve saber e fazer em sala de aula. E é por considerarmos que a constituição identitária está sempre em processo de mudança e re-conceitualizações que propomos este trabalho. Um melhor entendimento da complexidade da constituição identitária do futuro professor de língua através dos estudos já realizados pode colaborar para a re(construção) de paradigmas que favoreça identificações dos sujeitos com a profissão e consigo mesmo, pois também concebemos a identidade profissional como um dos múltiplos fios que compõem o tecido do "eu".

O objetivo deste trabalho é apresentar uma atualização de um estudo bibliográfico sobre a identidade profissional do professor de língua inglesa no Brasil, realizado por Quevedo-Camargo e Ramos em 2006, cujo levantamento de dados foi feito por meio eletrônico. Desse modo, vamos nos concentrar nas publicações realizadas após o estudo de 2006, abordando, portanto as pesquisas de 2006 a outubro de 2008, de maneira a verificar 
tanto as contribuições destes estudos quanto as possíveis descobertas e diferenças em relação a estudos anteriores. Esperamos contribuir - como também sugerem Quevedo-Camargo e Ramos (no prelo) - para um inventário de elementos constitutivos da identidade do professor de língua inglesa no cenário brasileiro. Como este estudo pretende atualizar o de QuevedoCamargo e Ramos, utilizamo-nos dos mesmos pressupostos metodológicos e da mesma organização do artigo, de modo a facilitar e possibilitar a continuidade dos conhecimentos já elencados pelas autoras.

\section{Metodologia}

A coleta foi realizada através da Internet utilizando-se das ferramentas de busca Google e Google Scholar, para o período de 2006 a outubro de 2008. Utilizamos como palavras-chave para a pesquisa os termos "identidade do professor de inglês", "identidade do professor de língua inglesa", "identidade profissional do professor de língua inglesa" e “identidade profissional do professor de inglês". Outro critério utilizado foi a presença da palavra identidade do título do trabalho.

O conjunto total de textos encontrados foram 6 estudos, entre eles 4 artigos e 2 dissertações de Mestrado. Também seguindo o modelo de trabalho do artigo mencionado, analisaremos os estudos de acordo com os seguintes tópicos: objetivos, definição de identidade, fundamentação teórica, metodologia e descobertas. Mantemos as mesmas perguntas de pesquisa, a saber:

1. Que características são recorrentes nas pesquisas sobre a identidade profissional de professores de inglês no Brasil?

2. Como as pesquisas brasileiras podem ser caracterizadas?

3. Que problemas podem ser levantados nas pesquisas brasileiras referentes à identidade profissional do professor brasileiro?

Entretanto, escolhemos acrescentar uma pergunta de pesquisa visando à verificação de mudanças referentes a estes tópicos em relação ao estudo anterior:

4. Se há diferenças em relação ao estudo anterior, em que estas se concentram?

\section{Apresentação dos trabalhos}

No quadro abaixo, apresentamos os trabalhos encontrados de acordo com os tópicos analisados e em seguida tecemos considerações sobre a visão geral de cada trabalho. Apresentamos as pesquisas em 2 quadros. $\mathrm{O}$ primeiro mostra os artigos encontrados. $\mathrm{O}$ 
segundo, as dissertações. Em ambos os quadros podem ser visualizadas as categorias de análise utilizadas para tal pesquisa.

\section{Quadro 1: Artigos}

\begin{tabular}{|c|c|c|c|c|c|}
\hline $\begin{array}{l}\text { Autor/ano } \\
\text { Título }\end{array}$ & Objetivos & $\begin{array}{l}\text { Definição de } \\
\text { identidade }\end{array}$ & $\begin{array}{l}\text { Fundamentação } \\
\text { teórica }\end{array}$ & Metodologia & Descobertas \\
\hline $\begin{array}{l}\text { OLIVEIRA } \\
\text { (2006) } \\
\text { De professor } \\
\text { a show- } \\
\text { person: } \\
\text { crenças } \\
\text { sobre a } \\
\text { identidade } \\
\text { do professor } \\
\text { de língua } \\
\text { inglesa nas } \\
\text { escolas } \\
\text { públicas do } \\
\text { Paraná. }\end{array}$ & 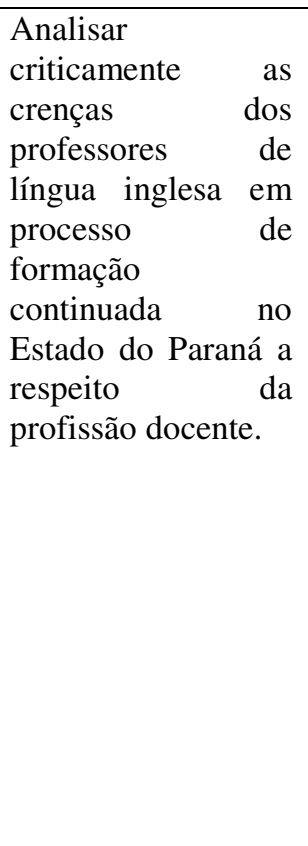 & - não consta & $\begin{array}{l}\text { - Princípios teóricos } \\
\text { metodológicos da } \\
\text { Análise crítica do } \\
\text { Discurso } \\
\text { (FAICLOUGH, } \\
\text { 2001) por meio do } \\
\text { modelo } \\
\text { tridimensional de } \\
\text { análise pelo autor e } \\
\text { Gramática Sistêmica } \\
\text { Funcional } \\
\text { (HALLIDAY, 2004) } \\
\text { através do sistema de } \\
\text { transitividade da } \\
\text { metafunção } \\
\text { ideacional. }\end{array}$ & $\begin{array}{l}\text { questionário } \\
\text { respondido por } 12 \\
\text { professores. }\end{array}$ & $\begin{array}{c}\text { - a nova } \\
\text { “identidade"do } \\
\text { professor } \\
\text { (mediador, } \\
\text { parceiro, } \\
\text { motivador, show- } \\
\text { person) envolve } \\
\text { uma renegociação } \\
\text { das relações de } \\
\text { poder com os } \\
\text { alunos que passam } \\
\text { a ser parceiros e } \\
\text { não mais meros } \\
\text { alunos; } \\
\text { - há uma } \\
\text { homogeneização do } \\
\text { papel e da } \\
\text { identidade do } \\
\text { professor nas } \\
\text { práticas discursivas } \\
\text { contemporâneas. }\end{array}$ \\
\hline $\begin{array}{c}\text { RAMOS } \\
\text { (sem data) } \\
\text { A identidade } \\
\text { do professor } \\
\text { de ensino } \\
\text { médio no } \\
\text { norte } \\
\text { fluminense. }\end{array}$ & 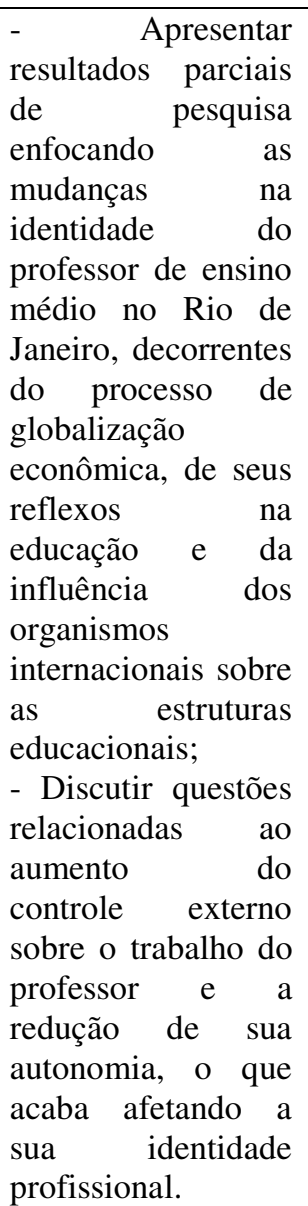 & - não consta & $\begin{array}{lr}\text { A perspectiva teórica } \\
\text { adotada em relação à } \\
\text { identidade } \\
\text { professor } \\
\text { nos estudos de Daseia-se } \\
\text { (1997) } \\
\text { identidades } \\
\text { profissionais; de } \\
\text { (2002) sobre } \\
\text { educaciais e } \\
\text { profissional reforma } \\
\text { Bernstein } \\
\text { sobre } \\
\text { simbólico } \\
\text { identidade. }\end{array}$ & 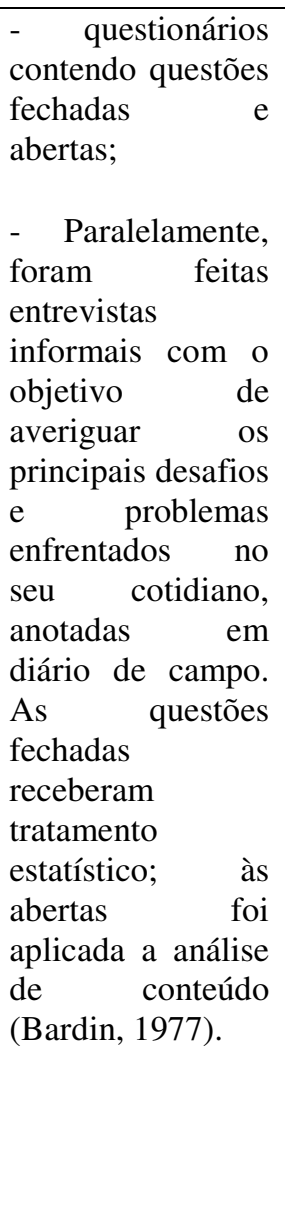 & 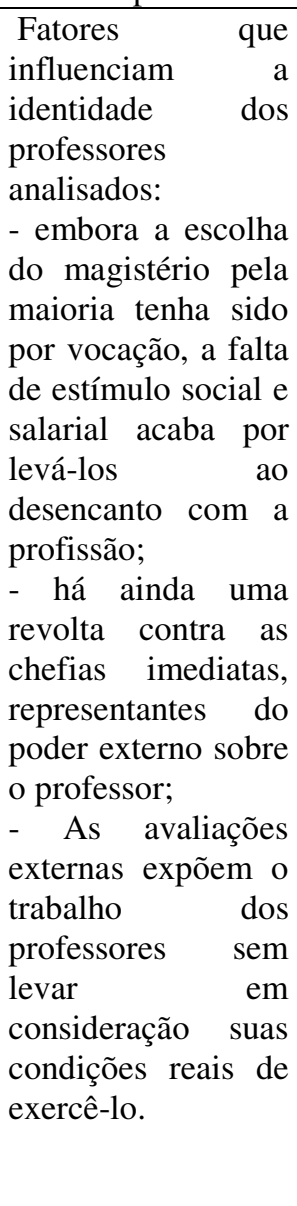 \\
\hline
\end{tabular}




\begin{tabular}{|c|c|c|c|c|c|}
\hline $\begin{array}{l}\text { TICKS (sem } \\
\text { data) } \\
\text { O perfil } \\
\text { identitário } \\
\text { do professor } \\
\text { de inglês } \\
\text { pré-serviço } \\
\text { subjacente a } \\
\text { narrativas de } \\
\text { história de } \\
\text { vida. }\end{array}$ & $\begin{array}{lr}\text { - contribuir para a } \\
\text { discussão } & \text { do } \\
\text { processo identitário } \\
\text { do professor } & \text { de } \\
\text { língua inglesa } & \text { por } \\
\text { meio } & \text { da } \\
\text { identificação } & \text { de } \\
\text { como esse } & \text { perfil } \\
\text { identitário } & \text { se } \\
\text { constitui } & \text { nos } \\
\text { discursos } & \text { dos } \\
\text { alunos } & \text { de } \\
\text { Letras/Inglês. } & \end{array}$ & $\begin{array}{l}\text { - construída } \\
\text { sócio- } \\
\text { historicament } \\
\text { e, não fixa, } \\
\text { não estável e } \\
\text { sempre em } \\
\text { processo. }\end{array}$ & $\begin{array}{l}\text { - MOITA LOPES, } \\
\text { 2003) Berger e } \\
\text { Luckkmann, } 1985 \text { e } \\
\text { FAIRCLOUGH, } \\
\text { 2003) }\end{array}$ & $\begin{array}{l}\text { - análise das } \\
\text { narrativas de } \\
\text { histórias de vida } \\
\text { orais e escritas a } \\
\text { partir da pergunta: } \\
\text { "O que te levou a } \\
\text { fazer } \\
\text { Letras/inglês? } \\
\text { Podes contar um } \\
\text { pouco da tua } \\
\text { história, da tua } \\
\text { experiência } \\
\text { escolar, da tua } \\
\text { relação com a } \\
\text { língua inglesa? }\end{array}$ & $\begin{array}{l}\text { - as participantes } \\
\text { mantém relação de } \\
\text { afinidade, afeição } \\
\text { com a língua } \\
\text { inglesa desde o } \\
\text { contexto escolar; } \\
\text { - diferenças } \\
\text { marcantes entre os } \\
\text { papéis atribuídos ao } \\
\text { professor de inglês } \\
\text { no contexto da } \\
\text { escola e do curso de } \\
\text { idiomas; } \\
- \text { as experiências } \\
\text { vivenciadas como } \\
\text { alunas, além de } \\
\text { meras lembranças, } \\
\text { ajudam a construi } \\
\text { e a projetar suas } \\
\text { futuras identidades } \\
\text { profissionais. }\end{array}$ \\
\hline $\begin{array}{l}\text { MARZARI } \\
\text { (sem data) } \\
\text { Formação e } \\
\text { identidade } \\
\text { de } \\
\text { professores } \\
\text { de Língua } \\
\text { (estrangeira). }\end{array}$ & 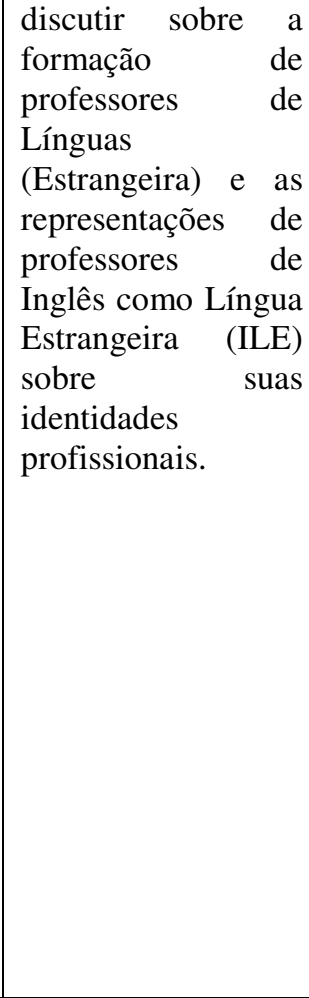 & - não consta & \begin{tabular}{lr}
\multicolumn{1}{c}{ prática $r$ crítico- } \\
reflexiva para & o \\
ensino de línguas, nos \\
pressupostos & sócio- \\
interacionistas/constr \\
utivistas vigotskianos \\
e nas & atuais \\
investigações & sobre \\
representação & e \\
identidade & de \\
aprendizes & e \\
professores de Língua \\
Inglesa.
\end{tabular} & -------- & 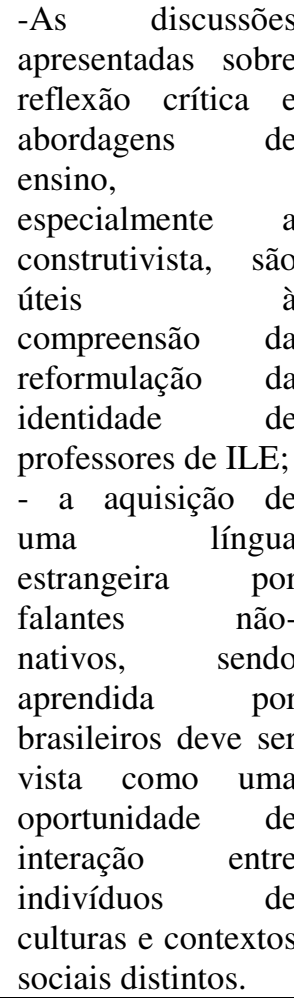 \\
\hline
\end{tabular}

Oliveira (2006) tem como objetivo analisar criticamente as crenças dos professores de língua inglesa em processo de formação continuada no Estado do Paraná a respeito da profissão docente através de um questionário respondido por 12 professores de língua inglesa da rede pública Estadual do Paraná. Fundamenta-se nos princípios teóricos metodológicos da Análise crítica do Discurso (FAIRCLOUGH, 2001) por meio do modelo tridimensional de análise proposto pelo autor e ainda na Gramática Sistêmica Funcional (HALLIDAY, 2004) 
através do sistema de transitividade da metafunção ideacional. A autora conclui que a nova identidade do professor é a de mediador, parceiro, motivador e 'show-person' e que esta nova identidade envolve uma renegociação das relações de poder com os alunos que passam a ser parceiros e não mais meros receptores. Além disso, salienta que há uma homogeneização do papel e da identidade do professor nas práticas discursivas contemporâneas devidas à mudança de papel social quanto às relações de poder em sala de aula.

O artigo de Ramos (sem data) busca apresentar resultados parciais de pesquisa enfocando as mudanças na identidade do professor de ensino médio no Rio de Janeiro, decorrentes do processo de globalização econômica, de seus reflexos na educação e da influência dos organismos internacionais sobre as estruturas educacionais. Objetiva também discutir questões relacionadas ao aumento do controle externo sobre o trabalho do professor e a redução de sua autonomia, o que acaba afetando a sua identidade profissional. Adota como perspectiva teórica em relação à identidade do professor os estudos de Dubar (1997) sobre identidades sociais e profissionais; de Day (2002) sobre reforma educacional e profissionalismo; e de Bernstein (1996) sobre controle simbólico e identidade. Utiliza como coleta de dados questionários contendo questões fechadas e abertas e entrevistas informais paralelas com o objetivo de averiguar os principais desafios e problemas enfrentados no cotidiano dos professores, anotadas em diário de campo. As questões fechadas receberam tratamento estatístico; às abertas foi aplicada a análise de conteúdo (Bardin, 1977). Conclui que embora a escolha do magistério pela maioria tenha sido por vocação, a falta de estímulo social e salarial acaba por levá-los ao desencanto com a profissão, que há ainda uma revolta contra as chefias imediatas (representantes do poder externo sobre o professor) e que as avaliações externas expõem o trabalho dos professores sem levar em consideração suas condições reais de exercê-lo, fatores todos que influenciam na constituição identitária dos professores.

O trabalho feito por Ticks (sem data) objetiva contribuir para a discussão do processo identitário do professor de língua inglesa por meio da identificação de como esse perfil identitário se constitui nos discursos dos alunos de Letras/Inglês. Para isso, ela se utiliza da análise das narrativas de histórias de vida orais e escritas a partir da pergunta: "O que te levou a fazer Letras/inglês? Podes contar um pouco da tua história, da tua experiência escolar, da tua relação com a língua inglesa? Sua concepção de identidade é aquela construída sóciohistoricamente, não fixa não estável e sempre em processo. Baseia-se nos pressupostos teóricos de Moita Lopes (2003), Berger e Luckkmann, (1985) e Fairclough (2003). Através da análise das narrativas de vida, a autora salienta que as participantes mantém uma relação 
de afinidade e afeição com a língua inglesa desde o contexto escolar e que há diferenças marcantes entre os papéis atribuídos ao professor de inglês no contexto da escola e do curso de idiomas. Aponta ainda que as experiências vivenciadas como alunas, além de meras lembranças, ajudam a construir e a projetar suas futuras identidades profissionais.

Marzari (sem data) em seu artigo "Formação e identidade de professores de Língua (estrangeira)" tem como foco problematizar a questão da formação de professores de Língua (Estrangeira) e as representações de professores de Inglês como Língua Estrangeira (ILE) sobre suas identidades profissionais. Para tal discussão, a autora fundamenta-se na prática crítico-reflexiva para o ensino de línguas, nos pressupostos sóciointeracionistas/construtivistas vigotskianos e nas atuais investigações sobre representação e identidade de aprendizes e professores de Língua Inglesa. Sua conclusão é de que as discussões apresentadas sobre reflexão crítica e abordagens de ensino, especialmente a construtivista, são úteis à compreensão da reformulação da identidade de professores de ILE e que a aquisição de uma língua estrangeira por falantes não-nativos, sendo aprendida por brasileiros deve ser vista como uma oportunidade de interação entre indivíduos de culturas e contextos sociais distintos.

Quadro 2: Dissertações

\begin{tabular}{|c|c|c|c|c|c|}
\hline $\begin{array}{l}\text { Autor/ano } \\
\text { Título }\end{array}$ & Objetivos & $\begin{array}{l}\text { Definição } \\
\text { de } \\
\text { identidade }\end{array}$ & $\begin{array}{l}\text { Fundamentação } \\
\text { teórica }\end{array}$ & Metodologia & Descobertas \\
\hline $\begin{array}{l}\text { FERNANDES } \\
\text { (2006) } \\
\text { Representações } \\
\text { e oconstrução } \\
\text { da identidade } \\
\text { do professor de } \\
\text { inglês. }\end{array}$ & $\begin{array}{l}\text { Investigar as } \\
\text { representações } \\
\text { de quatro } \\
\text { professores de } \\
\text { inglês de um } \\
\text { instituto de } \\
\text { idiomas para } \\
\text { verificar as } \\
\text { implicações } \\
\text { dessas } \\
\text { representações } \\
\text { em relação à } \\
\text { construção de } \\
\text { suas } \\
\text { identidades } \\
\text { profissionais. }\end{array}$ & $\begin{array}{l}\text { - identidade } \\
\text { vista como } \\
\text { fragmentada, } \\
\text { multifacetada, } \\
\text { plural, } \\
\text { inacabada; } \\
\text { - identidade } \\
\text { construída } \\
\text { através da } \\
\text { língua; } \\
\text { - definição } \\
\text { contrária a do } \\
\text { dicionário que } \\
\text { a define como } \\
\text { estática, pronta } \\
\text { e acabada; } \\
\text { - conceito que } \\
\text { só pode ser } \\
\text { definido e } \\
\text { discutido a } \\
\text { partir do do } \\
\text { sujeito e do } \\
\text { outro, nunca a } \\
\text { partir de um } \\
\text { ser isolado, } \\
\text { pronto e } \\
\text { dissociado de }\end{array}$ & 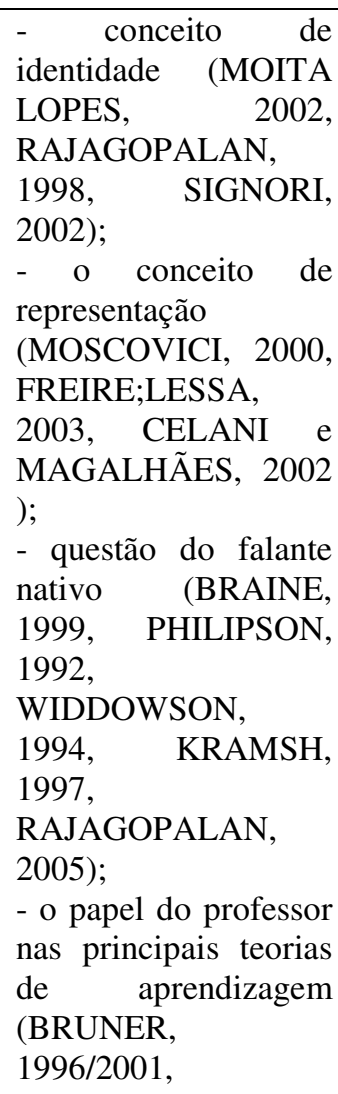 & $\begin{array}{l}\text {-Estudo de caso } \\
\text { fundamentado } \\
\text { em Nunan } \\
(1992) \text {, Liberali } \\
\text { e Liberali } \\
\text { (2002) e Rizini, } \\
\text { Castro e Sartor } \\
\text { (1999); } \\
\text { - entrevista } \\
\text { semi } \\
\text { estruturada. }\end{array}$ & $\begin{array}{l}\text { - representação } \\
\text { dos } \\
\text { participantes: } \\
\text { a) em relação a } \\
\text { língua inglesa } \\
\text { apontam para } \\
\text { uma língua de } \\
\text { inserção no } \\
\text { mundo, que abre } \\
\text { portas para o } \\
\text { mercado de } \\
\text { trabalho e que } \\
\text { está ligada à } \\
\text { questão cultural; } \\
\text { b) em relação a } \\
\text { identidade } \\
\text { construída como } \\
\text { falante da } \\
\text { língua: posição } \\
\text { de desprestígio e } \\
\text { desconforto } \\
\text { perante a a de a } \\
\text { falantes nativos; } \\
\text { - construção da } \\
\text { identidade do } \\
\text { professor de } \\
\text { língua inglesa }\end{array}$ \\
\hline
\end{tabular}




\begin{tabular}{|c|c|c|c|c|c|}
\hline & & $\begin{array}{l}\text { um mundo } \\
\text { social, cultural } \\
\text { e histórico. }\end{array}$ & $\begin{array}{l}\text { MIZUKAMI, } 1986, \\
\text { WILLIAMS; } \\
\text { BURDEN, } \\
\text { VYGOTSKI } \\
\text { 1934/2003, } \\
\text { MILHOLLAN; } \\
\text { FORISHA, 1978). }\end{array}$ & & $\begin{array}{l}\text { parece estar } \\
\text { sempre } \\
\text { estabelecida } \\
\text { numa relação de } \\
\text { "falta de"; } \\
\text { - identidade } \\
\text { construída na } \\
\text { relação entre a } \\
\text { busca de algo } \\
\text { idealizado e a } \\
\text { frequente falta } \\
\text { de algo para se } \\
\text { atingir este ideal; } \\
\text { - forte influência } \\
\text { do inglês como } \\
\text { língua } \\
\text { hegemônica na } \\
\text { construção das } \\
\text { representações e } \\
\text { das identidades } \\
\text { dos professores. }\end{array}$ \\
\hline $\begin{array}{l}\text { MARQUES } \\
\begin{array}{ll}\text { (2007) } \\
\text { Representação } \\
\text { e identidade: } \\
\text { uma análise do } \\
\text { discurso de } \\
\text { professores } \\
\text { inglês } \\
\text { escolas de } \\
\text { idiomas. }\end{array} \\
\end{array}$ & $\begin{array}{l}\text { - analisar as } \\
\text { representações } \\
\text { construídas no } \\
\text { discurso de } \\
\text { professores } \\
\text { brasileiros de } \\
\text { escolas de } \\
\text { idiomas para } \\
\text { compreender } \\
\text { mais ampla e } \\
\text { profundamente } \\
\text { seus aspectos } \\
\text { identitários. }\end{array}$ & $\begin{array}{l}\text { - construidas } \\
\text { socio- } \\
\text { históricamente, } \\
\text { marcada pela } \\
\text { transitoriedade } \\
\text { e pela } \\
\text { fragmentação e } \\
\text { formadas na } \\
\text { relação com o } \\
\text { outro. } \\
\text { Processo } \\
\text { nunca } \\
\text { completado, } \\
\text { eterno porvir; } \\
\text { - é construída e } \\
\text { marcada pela } \\
\text { diferença. }\end{array}$ & 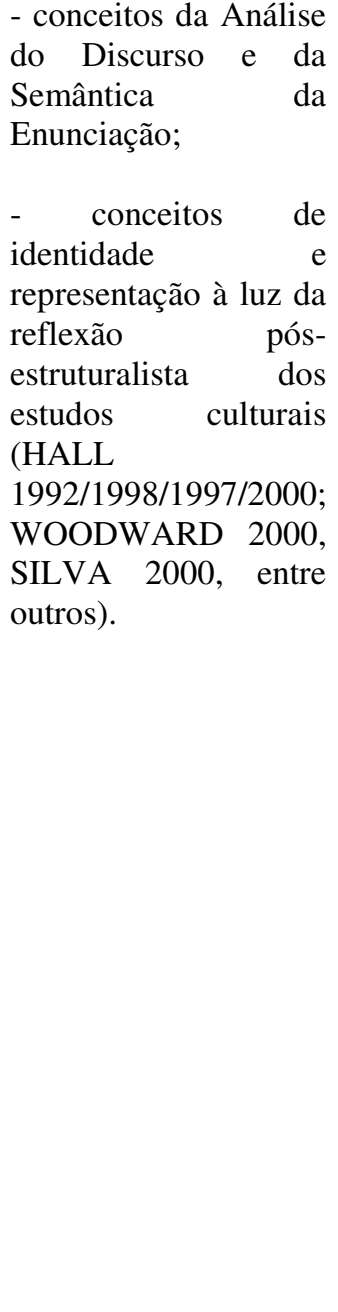 & $\begin{array}{l}\text { - gravações de } \\
\text { entrevistas em } \\
\text { áudio } \\
\text { analisadas à luz } \\
\text { dos } \\
\text { pressupostos } \\
\text { teóricos da } \\
\text { Análise do } \\
\text { discurso de } \\
\text { linha francesa, } \\
\text { da Semântica } \\
\text { da Enunciação } \\
\text { e teoria } \\
\text { polifônica de } \\
\text { Ducrot (1984). }\end{array}$ & 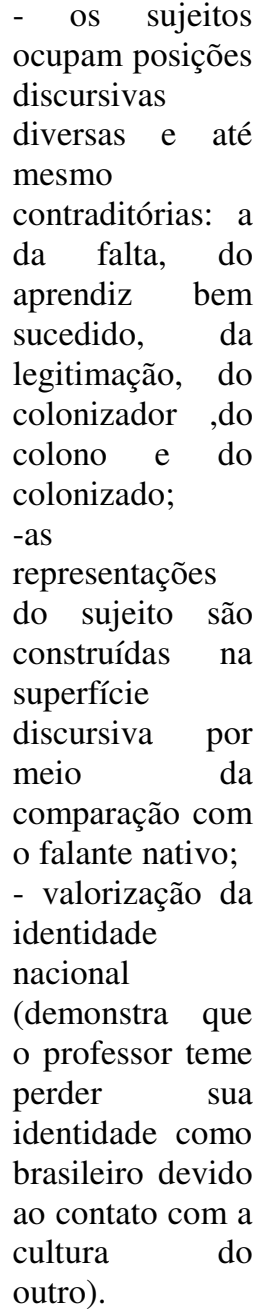 \\
\hline
\end{tabular}

A pesquisa de FERNANDES (2006), sob o título de "Representações e construção da identidade do professor de inglês" objetiva investigar as representações de quatro professores de inglês de um instituto de idiomas para verificar as implicações dessas representações em 
relação à construção de suas identidades profissionais, sua pesquisa busca responder três perguntas: "Qual a representação que os sujeitos têm sobre a língua inglesa? Qual a representação dos professores a respeito de si mesmos como falantes de língua inglesa? Como essas representações dos professores de inglês influenciam na construção de suas identidades? Fernandes concebe a identidade como sendo fragmentada, multifacetada, plural, inacabada e construída através da língua. A autora defende um conceito de identidade - baseado em Moita Lopes (2002), Rajagopalan (1998) e Signori (2002) - que só pode ser definido e discutido a partir do sujeito e do outro, nunca a partir de um ser isolado, pronto e dissociado de um mundo social, cultural e histórico. Desse modo, afasta-se da definição do dicionário que a concebe como estática, pronta e acabada. Fernandes utiliza-se também como fundamentos teóricos o conceito de representação (MOSCOVICI, 2000, Freire e Lessa, 2003, CELANI; MAGALHÃES, 2002 ), da questão do falante nativo (BRAINE, 1999, PHILIPSON, 1992, WIDDOWSON, 1994, KRAMSH, 1997, RAJAGOPALAN, 2005) e do papel do professor nas principais teorias de aprendizagem (BRUNER, 1996/2001, MIZUKAMI, 1986, WILLIAMS; BURDEN, 1997, VYGOTSKI 1934/2003, MILHOLLAN; FORISHA, 1978), valendo-se de um estudo de caso fundamentado em Nunan (1992), Liberali e Liberali (2002) e Rizini, Castro e Sartor (1999). Ela salienta que a representações dos participantes em relação a língua inglesa apontam a) para uma língua de inserção no mundo, que abre portas para o mercado de trabalho e que está ligada a questão cultural e b) que a identidade construída como falante da língua se dá por uma posição de desprestígio e desconforto perante a falantes nativos. A autora reforça que a construção da identidade do professor de língua inglesa parece estar sempre estabelecida numa relação de "falta de" porque esta identidade é construída na relação entre a busca de algo idealizado e a freqüente falta de algo para se atingir este ideal. Fernandes finaliza afirmando que há uma forte influência do inglês como língua hegemônica na construção das representações e das identidades dos professores.

O trabalho de Marques (2007), "Representação e identidade: uma análise do discurso de professores de inglês de escolas de idiomas" busca analisar as representações construídas no discurso de 4 professores brasileiros de escolas de idiomas através de gravações de entrevistas em áudio analisadas à luz dos pressupostos teóricos da Análise do discurso de linha francesa, da Semântica da Enunciação e teoria polifônica de Ducrot (1984) para compreender mais ampla e profundamente seus aspectos identitários. $\mathrm{O}$ autor focaliza as representações dos sujeitos sobre o ensino-aprendizagem de língua estrangeira, o povo brasileiro, o nativo de língua inglesa e as línguas portuguesa e inglesa com a hipótese de que os discursos dos sujeitos, permeado por discursos que circulam na sociedade, tendem a 
desqualificar aspectos da identidade e da cultura dos brasileiros e a legitimar aspectos da identidade e da cultura de nativos de países de língua inglesa. Baseando-se nos conceitos de identidade e representação à luz da reflexão pós-estruturalista dos estudos culturais (HALL 1992/1998/1997/2000; WOODWARD 2000, SILVA 2000, entre outros), concebe a identidade como construída socio-históricamente, marcada pela transitoriedade e pela fragmentação e formadas na relação com o outro, assim como um processo nunca completado, eterno porvir que é construído e marcado pela diferença. O autor destaca que entre os discursos que constituem o sujeito, estão o discurso do inglês como língua internacional, o discurso neoliberal da qualidade total, o discurso das abordagens e métodos de ensino de línguas estrangeiras e o discurso colonial. Através da análise, conclui que os sujeitos ocupam posições discursivas diversas e até mesmo contraditórias, como a da falta, do aprendiz bem sucedido, da legitimação, do colono e do colonizado. Revela ainda que as representações do sujeito são construídas na superfície discursiva por meio da comparação com o falante nativo, mas que há um discurso emergente de resistência pela valorização da identidade nacional (o que demonstra que o professor teme perder sua identidade como brasileiro devido ao contato com a cultura do outro).

\section{Retomando as categorias de análise e as perguntas de pesquisa}

Retomamos agora as categorias de análise de modo a verificar as similaridades e diferenças destes trabalhos em relação aos estudos já analisados. Faremos referências novamente aos estudos analisados no trabalho de Quevedo-Camargo e Ramos (no prelo).

Estas autoras mostram que os objetivos propostos pelos autores se diferenciam por dois aspectos, a saber: 1) pelo enfoque na formação inicial ou continuada e 2) pela análise da visão do professor sobre si mesmo ou a visão dos outros sobre o professor. Notamos que este mesmo parâmetro continua a ser verdadeiro. Observamos, portanto, que a maioria dos estudos concentram-se na constituição identitária de professores em serviço (4 estudos versus1 da formação inicial e 1 da formação continuada) e contemplam as representações dos próprios professores (5 pesquisas versus 1 que foca na visão de especialistas). Nota-se que Marques (2007), Fernandes (2006) e Ramos (sem data) concentram-se em analisar as representações construídas no discurso de professores brasileiros para compreender aspectos identitários, através das implicações de suas próprias representações em relação à construção de suas identidades profissionais. Estes autores concentram-se nos professores em serviço e contemplam a visão dos próprios professores sobre si mesmo e seu trabalho. Somente Ramos (sem data) concentra seus estudos em professores de escolas públicas enquanto Marques 
(2007) e Fernandes (2006) voltam seu olhar para professores de cursos de idiomas privados. Ticks (sem data) e Marzari (sem data), entretanto, se voltam à discussão do processo identitário do professor de língua inglesa na formação inicial, embora a primeira baseie-se nos próprios discursos dos alunos de Letras e a segunda lance seu olhar para a opinião dos especialistas sobre a constituição da identidade. Apenas Oliveira (2006) interessa-se pela constituição identitária dos professores em formação continuada de professores de língua inglesa no Estado do Paraná mostrando que uma "nova identidade" tem sido concebida por estes professores devido à mudança do papel social do professor em sala de aula: de professor a show-person.

Quanto à definição de identidade apresentada nas pesquisas, três estudos - Oliveira (2006), Ramos (sem data) e Marzari (sem data) - não apresentam definição de identidade. Os outros três estudos preocupam-se em defini-la e assumir uma posição perante a visão de identidade em que se baseiam. Entre estes estão os trabalhos de Ticks (sem data), Fernandes (2006) e Marques (2007), que a definem pela mesma perspectiva pós-estruturalista, concebendo-a como fragmentada, multifacetada, instável, construída sócio-historicamente na relação com o outro, inacabada, plural e marcada pela diferença, o que parece ser consenso de especialistas da linguagem como denuncia o próprio construto teórico utilizado por tais pesquisas.

Assim, no que se refere à utilização dos construtos teóricos, as pesquisas baseiam-se em variados pressupostos (análise crítica do discurso, Gramática Sistêmica funcional, identidades sociais e profissional (Dubar), sócio-interacionismo/construtivismo Vigotskiano, Semântica da Enunciação, e conceito de representação). Ao tratar especificamente da identidade, notamos a predominância dos conceitos defendidos à luz da reflexão pósestruturalista dos estudos culturais (HALL 1992/1998/1997/2000; WOODWARD 2000, SILVA 2000) e também nos estudos de Moita Lopes, (2002) Rajagopalan (1998) Signorini (2002).

A respeito dos procedimentos metodológicos, os autores utilizaram-se de questionários (Oliveira, 2006 e Ramos, sem data), análise de história de vida (Ticks, sem data), entrevistas gravadas em áudio (Marques, 2007 e Fernandes, 2006), estudo de caso (Fernandes, 2006) e pesquisa bibliográfica (Marzari, sem data). Podemos salientar aqui que os instrumentos utilizados casam com a idéia de identidade fragmentada e plural ao conseguir captar as diferentes nuances e até mesmo as contradições que co-existem na identidade de cada sujeito.

Por fim, verificamos que esses estudos salientam diferentes aspectos que constituem a identidade profissional do professor de língua e que reforçam a idéia de que a identidade é 
construída socio-historicamente, na relação com o outro e está sempre em processo. Nos estudos analisados, ela aparece vinculada a vários contituintes, a saber:

1) Contexto social :a) a falta de estímulo social e salarial leva ao desencanto com a profissão; b) a homogeneização do papel e da identidade do professor nas práticas contemporâneas; c) as diferenças marcantes entre os papéis atribuídos ao professor de inglês no contexto da escola e do curso de idiomas; d) a forte influência do inglês como língua hegemônica na construção das representações e das identidades dos professores; e) o fato da língua inglesa apontar para uma língua de inserção no mundo, que abre portas para o mercado de trabalho e que está ligada a questão cultural;

2) Relações no trabalho: a mudança no papel social e relações de poder do professor: de professor a show-person;

3) Política educacional: avaliações externas expõem o trabalho do professor sem levar em consideração as condições para fazê-lo;

4) Concepções de aprender e ensinar: a) as discussões apresentadas sobre reflexão crítica e abordagens de ensino são úteis à compreensão da reformulação da identidade de professores de ILE; b) as experiências vivenciadas como alunas ajudam a construir e a projetar suas futuras identidades profissionais; c) as representações do sujeito são construídas na superfície discursiva por meio da comparação com o falante nativo; d) a aquisição de uma língua estrangeira por falantes não-nativos deve ser vista como uma oportunidade de interação entre indivíduos de culturas e contextos sociais distintos;

5) Conhecimentos lingüísticos: em relação a identidade construída como falante da língua: posição de desprestígio e desconforto perante a falantes nativos;

6) Histórias de experiências: os sujeitos ocupam posições discursivas diversas e até mesmo contraditórias: a da falta, do aprendiz bem sucedido, da legitimação, do colono e do colonizado;

7) Emoções: a identidade é construída na relação entre a busca de algo idealizado e a freqüente falta de algo para se atingir este ideal: a construção da identidade do professor de língua inglesa parece estar sempre estabelecida numa relação de "falta de";

8) Pessoal e profissional: a) a maioria decide ser professor "por vocação"; b) a crescente valorização da identidade nacional demonstra que o professor teme perder sua identidade como brasileiro devido ao contato com a cultura do outro; 


\section{Considerações finais}

Embora com uma amostra bastante limitada, podemos perceber que as características recorrentes nas pesquisas sobre identidade no âmbito temporal deste estudo baseiam-se na visão do próprio professor na relação de como este se vê enquanto profissional - como também percebido por Quevedo-Camargo e Ramos (no prelo) - e co-existe uma forte predominância da relação entre identidade e conhecimento lingüístico, como pôde ser percebido pelas falas dos sujeitos pesquisados nos estudos acima. Desse modo, a relação do profissional com a língua que ensina apresenta-se como o principal fator constituinte da identidade destes professores. A comparação constante com os padrões do falante nativo, a insegurança e incertezas quanto ao seu desempenho lingüístico e uma emergente valorização da identidade nacional brasileira presente nas pesquisas demonstram uma relação permeada de incertezas e conflitos que está sempre em busca de algo mais, numa relação de "falta de". O que se percebe, contudo, é que os saberes pedagógicos - também outro principal constituinte da identidade profissional dos professores - tampouco são mencionados, o que apresenta a ilusão de que ser bom professor é saber bem a língua.

As pesquisas encontradas também atendem às mesmas características do estudo anterior: não são pesquisas longitudinais, mas sim que focalizam determinados grupos em determinadas épocas. Quanto aos principais problemas apresentados, destacamos também a ausência de caráter intervencionista, mas percebemos uma tentativa de se inventariar os conhecimentos sobre identidade existente na literatura. Entretanto, o que parece estar ausente destas pesquisas é a relação entre identidade e a base de conhecimento necessária ao professor de línguas que vá além do conhecimento linguiístico. Reconhecemos a importância do conhecimento linguiístico, mas corroboramos a idéia de que há outros conhecimentos - tão importante quanto este - que constituem a identidade do professor e que talvez mereçam maior atenção nas pesquisas sobre identidade, pois apenas o estudo de Marzari (sem data) ressalta a relevância da base de conhecimentos necessária ao professor de línguas. Falar em base de conhecimentos necessários ao professor não implica contudo em defender uma visão essencialista de uma base de conhecimentos fixa, estável e obrigatória a todo professor. O que ressaltamos não é o fato de que o professor deveria ter certo "tipo de identidade", mas sim que outros aspectos constituem sua identidade profissional além da questão lingüística, como por exemplo, o saber-fazer, a transposição didática dos saberes científicos e a cultura escolar, tidos como constituintes de uma identidade sempre em processo, inacabada, multifacetada e fragmentada. 
Talvez um estudo que possibilitasse uma maior compreensão dos aspectos que influenciam a identidade profissional de professores novatos de língua inglesa na sua primeira prática como professor possa ser relevante.

Vários estudos enfatizam a relação entre teoria e prática, mas não necessariamente sobre a constituição identitária de futuros profissionais da língua neste processo de "aprender a ser professor”. A transição de aluno para professor estagiário, segundo Flores (2003), surge marcada pela consciência crescente de novas funções com implicações para a transformação da identidade profissional. Talvez outra sugestão poderia ser trabalhos que visassem possibilitar uma maior conscientização desta visão de discurso e de identidade construída sócio-historicamente desde o primeiro ano dos cursos de formação inicial que posicionassem os futuros professores como responsáveis também pelo seu processo de profissionalização. Estudos longitudinais que contemplem alunos iniciantes do Curso de Letras ou ainda pesquisas voltadas para a relevância do discurso do professor formador na constituição identitária dos futuros professores também têm muito a colaborar para melhores entendimentos da constituição identitária destes professores.

Em geral, podemos afirmar - sempre levando em conta o levantamento parcial realizado neste trabalho - 1) que os estudos sobre identidade têm recebido uma crescente atenção por parte dos pesquisadores a julgar pela quantidade de artigos encontrados no âmbito de dois anos - neste estudo - se comparado às pesquisas encontradas por Quevedo-Camargo e Ramos (no prelo) (também 6 pesquisas, embora estas estejam circunscritas no âmbito temporal de 1997 a 2006, portanto 9 anos); 2) que a visão de identidade predominante é a construída sócio historicamente, sempre em processo, inacabada, multifacetada e fragmentada; 3) que há um predomínio de pesquisas sobre professores em serviço; 4) que há ênfase na relação entre Identidade e conhecimento lingüístico; 5) que há poucos trabalhos sobre professores de escola pública e 6) que há poucos trabalhos sobre a relação entre Identidade e formação inicial de professores de língua inglesa.

Em suma, esperamos ter contribuído para o início de um levantamento de um possível inventário de elementos constitutivos da identidade do professor de língua inglesa no cenário brasileiro e sugerimos que talvez um mesmo levantamento como este que privilegie pesquisas acessíveis por outros canais - e não somente pelo eletrônico - possa enriquecer e contribuir ainda mais para os estudos sobre identidade.

\section{Referências Bibliográficas}

BAUMAN, Z. Identidade: entrevista a Benedetto Vecchi. Rio de Janeiro: Jorge Zahar, 2005. 
BLOCK, D. Second language identites. New York: Continuum, 2007.

BOHN, H. Professor: a imagem projetada na imprensa. Investigações em Lingüística Aplicada e Teoria Literária, Recife, v. 17, n. 2, p. 115-126, 2005.

BERNSTEIN, B. Pedagogía, control sombólico e identidad. Madrid:Morata, 1996.

BARDIN, L. Análise de conteúdo. Edições 70, Lisboa,1977.

BERGER, P.; LUCKMANN, T. A construção social da realidade. Petrópolis: Vozes, 1985.

BRAINE, G. Non-native educators inEnglish Language TEaching. New Jersey. Lawerence Erlbaum Associate Publishers, 1999.

BRUNER, J. Actual minds, possible worlds. Cambridge: Harvard University Press, 1986.

BRUNER, J. (1996). A cultura da educacao. São Paulo, Artmed, 2001.

CELANI, M.A.A.; MAGALHAES, M.C.C. Representacoes de professores de ingles como lingua estrangeira sobre suas identidades profissionais: uma proposta de reconstrução. In: MOITA LOPES, L.P. e BASTOS, L.C (org.) Identidades: recortes multi e interdisciplinares. Campinas, Mercado das Letras

CORACINI, M. J. Identidade e discurso: (des)construindo subjetividades. Campinas: Ed. da UNICAMP, 2003.

DUBAR, C. A socialização: construção das identidades sociais e profissionais. Porto: Porto Editora, 1997.

DAY, C. School reform and transitions in teacher professionalism and identity. International Journal of Educational Research, 37:677-692). 2002.

FAIRCLOUGH, N. Discourse and social change. Cambridge: Polity Press, 1992a. Discurso e mudança social. Tradução de Isabel Magalhães. - Brasília: Editora Universidade de Brasília, 2001.

FAIRCLOUGH, N.. Analysing discouse: Textual analysis for social research. London/New York: Routledge, 2003.

FERNANDES, C. S. Representações e construção da identidade do professor de inglês. 2006. Dissertação. (Mestrado em Estudos Pós-Graduados em Lingüística Aplicada e Es) Pontifícia Universidade Católica de São Paulo, São Paulo.

FLORES, M. A. Aprender a ser professor: dilemas e des(continuidades). Revistas de Estudos Curriculares, Portugal, v. 1, n. 2, p. 189-212, 2003.

FREIRE, M.M; LESSA A. B.C. Professores de ingles da rede púbica: suas representacoes, seus repertórios e nossas interpretacoes. In: Barbara L. e RAMOS, L.C.G (org.) Reflexao e acoes no ensino e aprendizagem de linguas. Campinas, Mercado das Letras, 2003.

KRAMSH, C. The privilege of the nonnative speaker. PMLA, 12, 359-369, 1997. 
HALL, S. A identidade cultural na pós-modernidade. Rio de Janeiro: DP\&A, 1997; 2000.

HALL, S. Representation: Cultural representations and Signifying Practices. New York, Sage Publications, 1997.

HALL, S. Quem precisa de identidade? In: Silva, T. T. (org.) identidade e diferenca: a perspectiva dos Estudos culturais. Trad. De Tomaz Tadeu da Silva. Petropolis, Vozes, 2000, PP-103-133.

HALLYDAY, M.A.K. An introduction to functional grammar. London: Arnold, 2004.

LIBERALI, A; LIBERALI, F.C. Metodologia de pesquisa em ciências humanas: alguns aspectos fundamentais. (mimeo)

MOITA LOPES, L. P. Identidades fragmentadas: A construção discursiva de raça, gênero e sexualidade em sala de aula. Campinas: Mercado de Letras, 2002.

MOITA LOPES, L. P. (Org.). Discursos de identidades: Discurso como espaço de construção de gênero, sexualidade, raça, idade e profissão na escola e na família. Campinas, SP: Mercado de Letras, 2003.

MIZUKAMI, M.G.M. Ensino: as abordagens do processo. São Paulo, EPU, 1986.

MILHOLLAN, F.; FORISHA, B. Skinner e Rogers. Sao Paulo, Summus Editorial, 1978.

MARQUES, L. O. C. Representação e identidade: uma análise de discurso de professores de inglês de escola de idiomas. 2007. Dissertação. (Mestrado em Estudos Lingüísticos e Literários em Inglês) - Faculdade de Filosofia, Letras e Ciências Humanas da Universidade de São Paulo, São Paulo.

MARZARI, G. Q. Formação e identidade de professores de línguas (estrangeiras). Linguagens \& Cidadania, Santa Maria, n. 10, 2006. Disponível em: <http://www.ufsm.br/lec/02_03/Gabriela.htm>. Acesso em: 31 out.

NUNAN, D. Research Methods in Language learning. Cambridge, Cambridge University Press, 1992.

OLIVEIRA, N. B. De professor a show-person: crenças sobre a identidade do professor de língua inglesa nas escolas públicas do Paraná, 2006. Disponível em: $<$ http://www3.unisul.br/paginas/ensino/pos/linguagem/cd/Port/106.pdf $>$. Acesso em: 31 out. 2008.

PHILIPSON, R. Linguistic Imperialism. Oxford, England: Oxford university Press, 1992.

QUEVEDO-CAMARGO, G.; RAMOS, S. M. Reconsiderando pesquisas sobre a identidade profissional do professor de língua inglesa no contexto brasileiro. Acta Scientiarium: Language and Culture, Maringá, v.30, n.2, 2008. p. 189-19

RAMOS, L. M. P. C. ; PAEZ, E. F. . A identidade do professor do ensino médio do Norte Fluminense. In: III Congresso Online - Conhecimento aberto, sociedade livre, 2006. Anais do III Congresso, 2006. v. 1. p. 1-10. 
RAJAGOPALAN, K. O conceito de identidade em linguistica. E chegada a hora para uma construção radical? In: SIGNORINI, I. (org.). Linguagem e Identidade. São Paulo, Fapesp, Campinas, Mercado das Letras, 1998.

RAJAGOPALAN, K. Non-native speaker teachers of English and their anxieties: Ingredients for an experiment in an action research. In: Llurda E(org.) Non native language teachers: perceptions, challenges and contributions to the profession. Boston, Springer, 2005.

RIZZINI, I; CASTRO, M.R.; SARTOR, C.D. Pesquisando... Guias de metodologia de pesquisa para ciências sociais. Rio de Janeiro. Editora Universitaria Santa Úrsula, 1999.

SIGNORINI, Inês. (Org.) Língua(gem) e identidade: elementos para uma discussão no campo aplicado. Campinas, SP: Mercado de Letras, 4a. Impressão, 2006.

TICKS, L. K. O perfil identitário do professor de inglês pré-serviço subjacente a narrativas de história de vida. Anais do 4 Simposio Internacional de Estudos de Generos Textuais, vol $1: 1273-1286,2007$.

VYGOTSKY, L.S. Extracts from thought and language and mind in society. In: STIERER, B.; MAYBIN, J. (Ed.). Language, literacy and learning in educational practice. Clevedon: Multilingual Matters, 1994. p. 45-58.

VYGOSTKY, L.S. (1934) Pensamento e linguagem. São Paulo, Martins Fontes, 2003.

WIDDOWSON, H. The ownership of English. TESOL Quarterly, 28, 377-389, 1994.

WILLIAMS, M. e BURDENS, R.L. Psychology for Language Teachers: a social constructivism approach. Cambridge, Cambridge University Press, 1997

WOODWARD, K. Identidade e diferença: a perspectiva dos estudos culturais. Trad. De Tomaz Tadeu da Silva. Petropolis, Vozes, PP.7-72, 2000 